\title{
Comportamiento reproductivo del ácaro Varroa destructor (Mesostigmata: Varroidae) en celdas con cría de obrera y zángano en abejas africanizadas (Apis mellifera) en condiciones tropicales
}

\section{Reproductive behavior of the mite Varroa destructor (Mesostigmata: Varroidae) in worker and drone brood cells of Africanized honeybees (Apis mellifera) under tropical conditions}

\section{Comportamento reprodutivo do ácaro Varroa destructor (mesostigmata: varroidae) em células com criacao de operárias e zangões de abelhas africanizadas (Apis mellifera) em condições tropicais}

\section{Rafael A. Calderón-Fallas}

Programa Integrado de Patología Apícola, Centro de Investigaciones Apícolas Tropicales, Universidad Nacional, Heredia, Costa Rica. Correo electrónico: rafael.calderon.fallas@una.cr

Recibido: 15 de mayo de 2019 Corregido: 23 de setiembre de 2019 Aceptado: 1 de octubre de 2019

Resumen: Se estudió el comportamiento reproductivo del ácaro Varroa destructor en celdas con cría de obrera y zángano, durante el período de enero a agosto. Se utilizó 10 colmenas de abejas africanizadas (A. mellifera), ubicadas en el Centro de Investigaciones Apícolas Tropicales (CINAT), Lagunilla de Heredia, Costa Rica. La investigación se dividió en dos fases: a) la infestación artificial con el ácaro varroa de celdas con cría de obrera $(\mathrm{n}=732)$ y b) la infestación artificial de celdas con cría de zángano con los ácaros provenientes de las celdas de obrera $(n=362)$. Además, se comparó la habilidad reproductiva de varroa en ambos tipos de celda $(n=362)$, y se analizó en detalle los ácaros que no se reprodujeron en la cría de obrera y que fueron transferidos a la cría de zángano $(\mathrm{n}=85)$. Las celdas se revisaron 10 días después de infestadas artificialmente. Se evaluaron los siguientes parámetros reproductivos para cada ácaro: fertilidad, fecundidad, producción de hijas fértiles, producción de cría inmadura, producción de únicamente hembras, únicamente macho y no reproducción. En cría de obrera la fertilidad de varroa fue de un 76.9\%; sin embargo, solo el $16.5 \%$ de los ácaros produjo hijas fértiles, con un promedio de $1.3 \pm 0.5$ hijas fértiles. Mientras que, en cría de zángano, la fertilidad fue de un $79.3 \%$ y un $38.1 \%$ de los ácaros produjo hijas fértiles, con un promedio de $2.1 \pm 0.9$ hijas viables por celda. Al comparar la habilidad reproductiva de varroa se encontró que la fertilidad fue similar en ambos tipos de cría, no obstante, en celdas con cría de zángano una cantidad considerable de ácaros produjo hijas fértiles, mientras que en celdas de obrera se encontró únicamente un $13.8 \%$. Además, la producción de cría inmadura fue significativamente mayor en celdas con cría de obrera, superando el $40.0 \%$. Uno de los resultados más relevantes fue que el $74.1 \%$ de los ácaros que no tuvieron reproducción en la cría de obrera, se reprodujeron después de ser transferidos a celdas con cría de zángano, indicando que este tipo de cría es esencial para el desarrollo y crecimiento de la población del ácaro $V$. destructor en colmenas de abejas africanizadas bajo condiciones tropicales.

Palabras clave: Varroa destructor, abejas africanizadas, comportamiento reproductivo, cría de obrera, cría de zángano.

Abstract: The reproductive behavior of the mite Varroa destructor in worker and drone brood cells was studied from January to August. The study was conducted using 10 colonies of Africanized honeybees $(A$. mellifera) from the Tropical Beekeeping Research Center (CINAT), Lagunilla of Heredia, Costa Rica. The research was divided in two phases: a) artificial mites varroa infestation of worker brood cells $(n=732)$ and 
b) artificial infestation of drone brood cells with mites taken from the worker cells $(\mathrm{n}=362)$. In addition, the reproductive ability of varroa was compared between worker and drone brood cells $(n=362)$ and a detail analysis was conducted of the mites that did not reproduce in worker cells and were transferred into drone cells $(n=85)$. Each cell was examined for mite reproduction 10 days after infestation. The following parameters were measured for foundress female mites: fertility, fecundity, production of fertile females, production of immature offspring, only female or only male production and no reproduction at all. In worker brood cells, fertility rate was $76.9 \%$; however, only $16.5 \%$ of the mites produced fertile females with an average of $1.3 \pm$ 0.5 viable daughters. On the other hand, in drone brood cells, fertility rate was $79.3 \%$, and $38.1 \%$ of the mites produced fertile females, with an average of $2.1 \pm 0.9$ viable daughters. Comparing reproductive ability of the mites showed that the fertility rate was similar in both types of brood; however, a considerable amount of the mites produced fertile offspring in the drone cells, while only $13.8 \%$ were produced in the worker cells. Furthermore, the production of immature offspring was significantly higher (over $40 \%$ ) in the worker brood. One of the most relevant findings was that $74.1 \%$ of the mites that did not reproduce in worker cells were able to reproduce when transferred to drone cells, which indicates that drone brood is essential to the development and growth of varroa population in Africanized honeybees under tropical conditions.

Keywords: Varroa destructor, Africanized honeybees, reproductive behavior, worker brood, drone brood.

Resumo: O comportamento reprodutivo do ácaro Varroa destructor em células com criação de operárias e zangões foi estudado, durante o período de janeiro a agosto. Foram utilizadas 10 colméias de abelhas africanizadas (A. mellifera), localizadas no Centro de Pesquisa em Apicultura Tropical (CINAT), Lagunilla de Heredia, Costa Rica. A investigação foi dividida em duas fases: a) infestação artificial com o ácaro varroa em células com criação de operárias $(\mathrm{n}=732)$ e b) infestação artificial de células com criação de zangões com os ácaros das células de criação de operárias $(n=362)$. Além disso, a capacidade reprodutiva de varroa foi comparada nos dois tipos de células ( $\mathrm{n}=362$ ); foram analisados detalhadamente os ácaros que não se reproduziram na criação de operaria e que foram transferidos para a criação de zangões $(n=85)$. As células foram verificadas 10 dias após a infestação artificial. Os seguintes parâmetros reprodutivos para cada ácaro foram avaliados: taxa de fertilidade, taxa de fecundidade, produção de crias férteis, produção de crias imaduras, produção apenas de fêmeas, apenas de machos e não reprodutivos. Nas células com criação de operárias, a taxa de fertilidade do ácaro varroa foi de $76,9 \%$; no entanto, apenas $16,5 \%$ dos ácaros produziram crias férteis, com uma média de 1,3 $\pm 0,5$. Enquanto que nas células com criação de zangões, a taxa de fertilidade foi de $79,3 \%$ e $38,1 \%$ dos ácaros produziram crias férteis, com uma média de 2,1 $\pm 0,9$ de crias viáveis por célula. Ao comparar a capacidade reprodutiva do ácaro varroa verificou-se que a taxa de fertilidade foi semelhante nos dois tipos de criação; no entanto, nas células com criação de zangões, uma quantidade considerável de ácaros produziu crías férteis; enquanto nas células de operárias produziu apenas 13,8\%. Além disso, a produção de crias imaduras foi significativamente maior em células com criação de operárias, superior a 40,0\%. Um dos resultados mais relevantes foi que 74,1\% dos ácaros não se reproduziram nas células de criação de operárias e só foram capazes de se reproduzirem após serem transferidos para as células com criação de zangões, indicando que esse tipo de criação é essencial para o desenvolvimento e crescimento populacional do ácaro V. destructor em colméias de abelhas africanizadas em condições tropicais.

Palavras-chave: Varroa destructor, abelhas africanizadas, comportamento reprodutivo, criação de operárias, criação de zangões.

\section{Introducción}

La Varroosis es una parasitosis externa y contagiosa que afecta tanto a la cría, como a las abejas adultas. Esta enfermedad parasitaria es causada por el ácaro Varroa destructor Anderson y Trueman (Mesostigmata: Varroidae), el cual ha sido reportado como uno de los parásitos que más pérdidas 
económicas causa en la producción apícola a nivel mundial (De Jong 1997). El ácaro varroa depende de las abejas adultas para su transporte y al mismo tiempo se alimenta, antes de infestar una celda con cría para iniciar su ciclo reproductivo. El período en el cual el ácaro permanece sobre las abejas adultas se denomina forético (Vandame et al. 2000; Calis 2001).

Se debe indicar que el ácaro varroa se reproduce estrictamente en la cría operculada (Martin \& Kemp 1997). Algunos estudios han encontrado que tiene predilección por celdas con cría de zángano (Boot et al. 1995a; Beetsma et al. 1999). En su hospedero natural, la abeja A. cerana, la reproducción se lleva a cabo básicamente en cría de zángano, sin embargo, en abejas melíferas se reproduce tanto en cría de obrera como de zángano. La mayoría de los estudios realizados sobre la biología reproductiva del ácaro varroa, se han llevado a cabo en abejas de raza europea y en países con condiciones de clima templado, siendo la investigación en abejas africanizadas y en condiciones tropicales, muy escasa (Martin \& Kemp 1997; Calis et al. 1999; Medina et al. 2002). En Costa Rica, observaciones preliminares sobre la habilidad reproductiva del ácaro $V$. destructor en abejas africanizadas, indican diferencias importantes respecto a lo reportado en abejas europeas (Martin 1995b). Por ejemplo, en abejas africanizadas alrededor de un $30 \%$ de los ácaros no se reproducen en celda con cría de obrera, mientras que en las celdas con cría de zángano el ácaro varroa se reproduce de manera más exitosa (Calderón et al. 2003b).

Conocer la biología reproductiva de varroa en abejas africanizadas, es un aspecto fundamental para determinar su dinámica poblacional bajo condiciones tropicales. Además, algunos métodos de control biológico que se aplican en abejas europeas se basan en el principio de eliminar la cría operculada de zángano. Determinar que el ácaro varroa se reproduce exitosamente en la cría de zángano en abejas africanizadas, es un aspecto fundamental para implementar este método en condiciones tropicales (Boot et al. 1995a; Beetsma et al. 1999).

Por lo anterior, el objetivo del presente estudio es evaluar el comportamiento reproductivo del ácaro Varroa destructor (Mesostigmata: Varroidae) al ser transferido de celdas con cría de obrera a celdas con cría de zángano en abejas africanizadas. Específicamente, determinar si los ácaros que no se reproducen en la cría de obrera mejoran su capacidad reproductiva al ser transferidos a la cría de zángano.

\section{Materiales y métodos}

Ubicación geográfica y manejo general del apiario: El estudio se llevó a cabo en el Centro de Investigaciones Apícolas Tropicales (CINAT) de la Universidad Nacional, provincia de Heredia $\left(10^{\circ}\right.$ $01^{\prime} \mathrm{N}, 84^{\circ} 07^{\prime} \mathrm{O} ; 1130 \mathrm{msnm}$ ). El mismo se desarrolló de enero a agosto (enero-abril= época seca; mayo-agosto= época lluviosa). Se instaló un apiario formado por 10 colmenas de abejas africanizadas (A. mellifera). Ocho colmenas se utilizaron para investigar la biología reproductiva de varroa. Las dos colmenas restantes se emplearon para colectar ácaros de varroa para infestar las celdas. Cuando fue necesario y con el objetivo de aumentar la cantidad de cría de zángano en las colmenas, se introdujeron láminas estampadas (panales) con celdas para zángano (Ravazzi 1995).

Diseño experimental: La investigación se dividió en dos fases, la infestación artificial de celdas con cría de obrera con ácaros adultos de varroa y la infestación artificial de celdas con cría de zángano con ácaros 
Rev. Ciencias Veterinarias, Vol. 37, N² 2, [44-61], E-ISSN: 2215-4507, julio-diciembre, 2019

DOI: https://doi.org/10.15359/rcv.37-2.5

Ciencias

URL: http://www.revistas.una.ac.cr/index.php/veterinaria/index

provenientes de las celdas de obrera. El total de celdas analizadas para determinar la reproducción del ácaro $V$. destructor fue de 732 en cría de obrera y de 362 en cría de zángano. Esta cantidad permitió establecer diferencias significativas en su reproducción en los dos grupos de cría (obrera y zángano) (Calderón et al. 2003b).

Parámetros reproductivos: Los parámetros que se evaluaron para cada ácaro madre fueron los siguientes.

- Fertilidad: correspondió a todo ácaro con producción de cría (madura e inmadura) (CorrêaMarques et al. 2003).

- Fecundidad: cantidad de progenie producida por ácaro por celda durante un ciclo reproductivo (Medina et al. 2002; Corrêa-Marques et al. 2003).

- Producción de hijas fértiles: son aquellas celdas con presencia del macho y al menos una hija adulta. Este parámetro corresponde a los ácaros que contribuyen al crecimiento de la población del ácaro varroa en la colmena.

- Producción de cría inmadura: corresponde a las celdas en las que se determinó presencia de únicamente estadios inmaduros de varroa (huevo-protoninfa-deutoninfa) (Medina et al. 2002).

- Producción de únicamente hijas: celdas con presencia de hembra(s) adulta(s) y ausencia del macho adulto.

- Producción de únicamente macho: celdas con presencia del macho adulto y ausencia de hembras adultas, con posibilidad de observar cría inmadura (Corrêa-Marques et al. 2003).

- No reproducción: correspondió a aquellos ácaros que no produjeron progenie.

Habilidad reproductiva del ácaro $V$. destructor en celdas con cría de obrera: En la primera fase, la habilidad reproductiva del ácaro varroa se determinó en cría de obrera. En el presente estudio, la habilidad reproductiva fue definida como la capacidad del ácaro (madre) de reproducirse (Calderón et al. 2003a). Se seleccionaron en las colmenas experimentales, celdas de obrera que contenían larvas en estado avanzado de desarrollo (192 horas aproximadamente). Las celdas con cría se ubicaron en el panal utilizando láminas de transparencia, sobre las cuales se delineó un círculo con un marcador permanente. Estas láminas fueron adheridas temporalmente al panal con chinches metálicos de cabeza ancha. Luego de 4 a 5 horas (en promedio), el panal se trasladó al laboratorio donde se verificó las celdas que fueron selladas por las abejas. Los ácaros utilizados para la infestación artificial de la cría se colectaron únicamente de celdas de obrera que contenían pupas próximas a emerger. Para introducir el ácaro en las celdas de obrera recientemente operculadas, se realizó una pequeña incisión en la base del opérculo con una hoja de bisturí \#15. Con un pincel de brocha fina, el ácaro fue transferido al interior de la celda. Posteriormente, la celda se selló al colocar nuevamente el opérculo en su posición original. Este paso fue fundamental, debido a que cualquier anormalidad en el sellado de la celda, podía ser detectada por las abejas, las cuales removían la cría infestada artificialmente (la limpiaban). Una vez finalizada la infestación de las celdas, los panales se devolvieron a las colmenas experimentales. Después de 10 días de haber realizado la infestación artificial, cuando la cría tenía de 19 a 20 días de edad, las celdas se examinaron para determinar la reproducción de cada ácaro individualmente. La 
celda fue desoperculada, y la pupa removida y colocada en un plato de vidrio. Los ácaros presentes en la celda (maduros e inmaduros) fueron identificados utilizando el estereoscopio y registrados de acuerdo a la cantidad presente y a su estadio de desarrollo. Adicionalmente, el fondo de cada celda se revisó minuciosamente con una fuente de luz. Las celdas con cría de obrera se revisaron 10 días después de infestadas, debido a que todavía se pueden diferenciar los ácaros madre de sus hijas en fase adulta, ya que la pigmentación rojiza de estas últimas aún no se ha completado (Boot et al. 1995a). Además, la cría de obrera en abejas africanizadas permanece sellada por un período aproximado de 11.5 días, lo cual sugiere que al día 10 la abeja estaba próxima a emerger.

Comportamiento reproductivo del ácaro $V$. destructor en celdas con cría de zángano: La segunda fase inició una vez determinada la reproducción de cada ácaro madre en la cría de obrera, transfiriendo los ácaros inmediatamente a la cría de zángano. La metodología utilizada para la selección, el marcado, la infestación y la revisión de las celdas de zángano, fue similar a la descrita para las de obrera.

Las principales diferencias respecto a la cría de obrera, es que la cría de zángano una vez que es marcada, requiere de más horas para ser sellada (6-8 horas). Además, tienen un mayor tamaño que las de obrera (aproximadamente el doble) y se ubican en la periferia del panal. Por otra parte, aun cuando la cría de zángano permanece sellada por un período de 14 días, la revisión de la celda también se realizó al día 10 para diferenciar el ácaro madre de su progenie. Además, se debe indicar que, para determinar la cantidad de hijas fértiles producidas en la cría de zángano, se consideró el estadio de deutoninfa (móvil e inmóvil), debido a que en condiciones naturales las celdas de zángano permanecen selladas por 96 horas más, lo cual es suficiente tiempo para que la deutoninfa alcance el estadio adulto.

Comparación del comportamiento reproductivo del ácaro varroa en celdas con cría de obrera y de zángano, y análisis de los ácaros que no se reprodujeron en la cría de obrera y que fueron transferidos a la cría de zángano: De la mayoría de los ácaros de varroa se obtuvo datos de su habilidad reproductiva en la cría de obrera y en la cría de zángano, lo cual permitió comparar su comportamiento reproductivo. Además, se analizaron de manera específica los ácaros que no lograron reproducirse en las celdas de obrera y que fueron transferidos a las celdas de zángano, para determinar si mejoran su capacidad reproductiva (producción de cría: madura e inmadura).

Análisis de los datos: Los datos obtenidos sobre la reproducción del ácaro $V$. destructor en celdas de obrera y zángano, se analizaron mediante el método estadístico de Chi-cuadrado (Clarke 1989).

\section{Resultados}

\section{Habilidad reproductiva del ácaro $V$. destructor en celdas con cría de obrera}

El total de celdas con cría de obrera analizadas para determinar la reproducción del ácaro V. destructor fue de 732 , encontrándose una mortalidad del $2.3 \%$ en el ácaro madre.

Fertilidad: La fertilidad del ácaro varroa determinada en la cría de obrera fue del 76.9\% $(\mathrm{n}=732)$ (Cuadro 1). Para estimar este parámetro, se consideró todos los ácaros que produjeron progenie (madura e inmadura).

Producción de hijas fértiles: En el 16.5\% de las celdas $(n=732)$, se observó la presencia del macho y al menos una hija adulta (Cuadro 1), con un promedio de hijas fértiles de $1.3 \pm 0.5$. Del total de datos analizados, se obtuvo 160 hijas fértiles, las cuales contribuyen al crecimiento de la población del ácaro en 
la colmena. Debido a que la duración del periodo de cría sellada en celdas de obrera en abejas africanizadas es de 11.5 días, las deutoninfas inmóviles encontradas al día 10 del ciclo, no fueron consideradas, ya que la posibilidad de mudar a ácaros adultos es muy baja. Por lo anterior, el número de hijas fértiles fue estimado tomando en cuenta únicamente los ácaros jóvenes. No se encontraron diferencias significativas con respecto a la cantidad de hijas fértiles producidas durante la época seca y la lluviosa $(\mathrm{p}=0.26)$.

Fecundidad: El promedio de cría producida por ácaro fue de $2.9 \pm 1.3(\mathrm{n}=563)$, con un mínimo de un descendiente y un máximo de seis. En la mayoría de las celdas se encontró de dos a tres crías, lo cual corresponde a un 48\% $(n=563$. En total se observó 1667 descendientes, sin embargo, debe considerarse que no todos alcanzaron el estadio adulto.

Producción de cría inmadura: El porcentaje de ácaros que sólo produjo cría inmadura en celdas con cría de obrera corresponde a un 38.2\% ( $n=732)$. En este estudio, no se determinó cuales estadios inmaduros se presentaban con mayor frecuencia debido a que independientemente de su fase de desarrollo, ninguno de ellos tendría el tiempo suficiente para alcanzar el estadio adulto. En un $4 \%$ de los casos ( $n=21$ descendientes), se observó mortalidad en la cría inmadura, lo cual es un factor que limita el aumento poblacional del ácaro varroa. Se observaron diferencias significativas respecto a la presencia de cría inmadura y la época del año, siendo mayor su producción durante la época lluviosa $(\mathrm{p}=0.01)$.

Ácaros con producción de únicamente hijas o únicamente macho: Las celdas en las cuales se determinó la presencia de únicamente hijas adultas fue de un 8.5\% $(n=732)$. Mientras que aquellas con presencia de únicamente macho adulto, correspondió a un $13.7 \%$. La ausencia de hijas adultas afecta de manera directa el crecimiento de la población de varroa.

No reproducción: Los ácaros que no lograron reproducirse en la cría de obrera corresponden a un 23.1\% (n= 732) (Cuadro 1). Estos ácaros son aquellos que ingresan a la celda, se alimentan (presencia de heces), se observan saludables (movimiento, locomoción) pero no producen progenie. Este parámetro ha sido relacionado como uno de los factores más importantes en la tolerancia/resistencia de las abejas africanizadas hacia el ácaro varroa y es referido como la supresión reproductiva del ácaro (SMR, por sus siglas en inglés). No se encontró diferencias significativas respecto a la no producción de cría durante la época seca y la lluviosa $(\mathrm{p}=0.38)$.

Cuadro 1. Parámetros reproductivos del ácaro V. destructor en celdas con cría de obrera $(\mathrm{n}=732)$.

\begin{tabular}{ccc}
\hline Parámetro reproductivo & Número de celdas & Porcentaje \\
\hline Fertilidad & 563 & 76.9 \\
\hline No reproducción & 169 & 23.1 \\
\hline Parámetro reproductivo & & \\
\hline Hijas fértiles & Número de celdas & Porcentaje \\
Cría inmadura & 121 & 16.5 \\
Únicamente hembra & 280 & 38.2 \\
Únicamente macho & 62 & 8.5 \\
\hline
\end{tabular}




\section{Comportamiento reproductivo del ácaro varroa en celdas con cría de zángano}

El total de celdas de cría de zángano analizadas fue de 362, encontrándose un $7 \%$ de mortalidad del ácaro madre. Un aspecto a evaluar en las crías de zángano fue la sobreinfestación (presencia de 2 o más ácaros madre), determinada en un número considerable de celdas $(\mathrm{n}=24)$. Estas celdas fueron excluidas del análisis de los datos, debido a que no es posible determinar de manera específica (individual) la progenie de cada ácaro madre. Sin embargo, se debe señalar que, en condiciones naturales, celdas con sobreinfestación contribuyen al crecimiento poblacional de varroa.

Fertilidad: El porcentaje de ácaros madre que produjo progenie en las celdas con cría de zángano fue de un 79.3\% ( $n=362)$ (Cuadro 2).

Producción de hijas fértiles: En el 38.1\% de las celdas $(n=362)$, se observó la presencia del macho y de al menos una hija adulta (Cuadro 2), con un promedio de hijas fértiles de $2.1 \pm 0.9$. El total de hijas fértiles en las celdas de cría de zángano fue de 290. Debido a que la duración del periodo de cría sellada en celdas de zángano es de 14 días, tanto las deutoninfas móviles como las inmóviles encontradas al día 10 del ciclo fueron consideradas, ya que la posibilidad de mudar a ácaros adultos es alta. Por lo anterior, el número de hijas fértiles fue estimado considerando los ácaros jóvenes y el estadio de deutoninfa. Por otra parte, no se encontró diferencias significativas respecto a la producción de hijas fértiles durante la época seca y la lluviosa $(\mathrm{p}=1.00)$.

Fecundidad: El promedio de cría producida por ácaro en las celdas de zángano fue de $3.7 \pm 1.6$ ( $\mathrm{n}=$ 287), con un mínimo de un descendiente y un máximo de siete. La mayoría de las celdas presentó entre tres y cuatro crías, lo cual corresponde a un $46 \%$ de las celdas analizadas ( $n=287)$. En total se produjeron 1,102 descendientes, de los cuales no todos alcanzaron el estadio adulto.

Producción de cría inmadura: En 13.3\% de las celdas de zángano (n=362), se determinó la producción de cría inmadura. No hubo diferencias significativas, respecto a la producción de cría inmadura durante la época seca y la lluviosa $(\mathrm{p}=0.15)$.

Ácaros con producción de únicamente hijas o únicamente macho: Las celdas en las cuales se encontró la presencia de únicamente hijas adultas fue de un $15.2 \%(\mathrm{n}=362)$, por otro lado, aquellas con presencia de únicamente macho correspondió a un $12.7 \%(\mathrm{n}=362)$. La producción de sólo hijas $(\mathrm{p}=0.62)$ y sólo macho $(\mathrm{p}=1.00)$ en las celdas con cría de zángano, se comportó de manera similar durante las dos épocas del año.

No reproducción: Los ácaros que no produjeron progenie en celdas de zángano correspondieron a un $20.7 \%(n=362)$ (Cuadro 2). No se observó diferencias significativas respecto a la no producción de cría durante la época seca y la lluviosa, sin embargo, existe la tendencia de una mayor cantidad de ácaros que no se reproducen durante la época lluviosa $(\mathrm{p}=0.08)$. 
Rev. Ciencias Veterinarias, Vol. 37, N² 2, [44-61], E-ISSN: 2215-4507, julio-diciembre, 2019

DOI: https://doi.org/10.15359/rcv.37-2.5

URL: http://www.revistas.una.ac.cr/index.php/veterinaria/index

Cuadro 2. Parámetros reproductivos del ácaro V. destructor en celdas con cría de zángano ( $\mathrm{n}=362)$.

\begin{tabular}{ccc}
\hline Parámetro reproductivo & Número de celdas & Porcentaje \\
\hline Fertilidad & 287 & 79.3 \\
No reproducción & 75 & 20.7 \\
\hline Parámetro reproductivo & Número de celdas & \\
\hline Hijas fértiles & 138 & Porcentaje \\
Cría inmadura & 48 & 38.1 \\
Únicamente hembra & 55 & 13.3 \\
Únicamente macho & 46 & 15.2 \\
\hline
\end{tabular}

\section{Comparación de la habilidad reproductiva del ácaro $V$. destructor en celdas con cría de obrera y zángano}

Se comparó los diferentes parámetros reproductivos en un total de 362 ácaros, luego de determinar su habilidad reproductiva en celdas con cría de obrera y ser transferidos a celdas con cría de zángano.

Fertilidad: En celdas con cría de obrera se encontró una fertilidad del $76.5 \%$, la cual fue similar a la determinada en celdas con cría de zángano y que correspondió a un 79.3\% (Cuadro 5). No se encontraron diferencias significativas, con respecto a la fertilidad de varroa al compararla en los dos tipos de cría $\left(\mathrm{X}^{2}=0.78, \mathrm{p}=0.37\right)$.

Producción de hijas fértiles: En el $13.8 \%$ de las celdas de obrera se determinó la presencia de hijas fértiles, encontrándose un promedio de $1.4 \pm 0.5$ y un total de 67 hijas fértiles. Por otra parte, en el $38.1 \%$ de las celdas con cría de zángano se produjo hijas fértiles, con un promedio de $2.1 \pm 0.9$ y un total de 290 hijas fértiles. Al comparar la producción de hijas fértiles en los dos tipos de cría se encontró diferencias significativas $\left(\mathrm{X}^{2}=55.4, \mathrm{p}<0.01\right)$.

Un aspecto relevante, es el alto porcentaje de ácaros que no logró reproducirse adecuadamente en la cría de obrera (producción de estadios inmaduros, un sólo sexo o no reproducción) y que produjo hijas fértiles al ser transferidos a la cría de zángano (Cuadro 3). Por otra parte, un $7.0 \%$ de los ácaros produjo hijas fértiles en ambos tipos de cría y sólo un $7.3 \%$ de los ácaros que produjo cría fértil en celdas de obrera no logró producirla en celdas de zángano. 
Cuadro 3. Ácaros que mejoraron su reproducción al ser transferidos de celdas con cría de obrera a celdas con cría de zángano $(\mathrm{n}=362)$.

\begin{tabular}{cccc}
\hline \multicolumn{2}{c}{ Transferencia de ácaros de } & Número de celdas & Porcentaje \\
Cría de obrera & Cría de zángano & & \\
\hline Cría inmadura & Hijas fértiles & 53 & 15.0 \\
Únicamente hembra & Hijas fértiles & 12 & 3.3 \\
Únicamente macho & Hijas fértiles & 20 & 5.5 \\
No reproducción & Hijas fértiles & 31 & 8.5 \\
\hline & Total & $\mathbf{1 1 6}$ & $\mathbf{3 2 . 3}$ \\
\hline
\end{tabular}

Fecundidad: En las celdas de obrera el promedio de cría fue de $2.9 \pm 1.4(\mathrm{n}=277)$, con un mínimo de un descendiente y un máximo de seis, obteniéndose un total de 828 descendientes. Por otra parte, en las celdas de zángano, el promedio de cría encontrado fue de $3.8 \pm 1.6(n=287)$, con un mínimo de un descendiente y máximo de siete, y un total de 1102 crías.

Producción de cría inmadura: En las celdas de obrera un $40.6 \%$ de los ácaros produjo cría inmadura, mientras que en la cría de zángano este parámetro correspondió a un 13.2\%, encontrándose diferencias significativas $\left(\mathrm{X}^{2}=69, \mathrm{p}<0.01\right)($ Cuadro 5).

Ácaros con producción de únicamente hijas: En un 7.2\% de las celdas de obrera, se observó la presencia de únicamente hijas adultas. Por otro lado, en la cría de zángano este parámetro correspondió a un 15.2\% (Cuadro 5). Al comparar este resultado en ambos tipos de celda, se encontró diferencias significativas $\left(\mathrm{X}^{2}=12.31, \mathrm{p}<0.01\right)$.

Ácaros con producción de únicamente macho: La producción de únicamente macho adulto fue similar en los dos tipos de cría, correspondiendo a un $14.9 \%$ en obrera y a un $12.8 \%$ en zángano $\left(\mathrm{X}^{2}=\right.$ $0.74, \mathrm{p}=0.40)$ (Cuadro 5).

Ácaros que se reprodujeron, pero no lograron producir hijas fértiles: Un $27.1 \%$ de los ácaros analizados se reprodujo tanto en las celdas de obrera como en las de zángano, sin embargo, produjeron únicamente cría inmadura o cría de un sólo sexo, lo cual no contribuye al crecimiento de la población de varroa (Cuadro 4). 
Rev. Ciencias Veterinarias, Vol. 37, N² 2, [44-61], E-ISSN: 2215-4507, julio-diciembre, 2019

DOI: https://doi.org/10.15359/rcv.37-2.5

URL: http://www.revistas.una.ac.cr/index.php/veterinaria/index

Cuadro 4. Ácaros que se reprodujeron en las celdas de obrera y zángano pero que no lograron producir hijas fértiles ( $\mathrm{n}=362)$.

\begin{tabular}{llcc}
\hline \multicolumn{1}{c}{$\begin{array}{c}\text { Transferencia de ácaros de } \\
\text { Cría de obrera } \rightarrow \text { Cría de zángano }\end{array}$} & Número de celdas & Porcentaje \\
\hline Cría inmadura & Cría inmadura & 25 & 7.0 \\
Cría inmadura & Únicamente hembra & 22 & 6.1 \\
Cría inmadura & Únicamente macho & 11 & 3.0 \\
Únicamente hembra & Únicamente hembra & 4 & 1.1 \\
Únicamente hembra & Cría inmadura & 2 & 0.5 \\
Únicamente hembra & Únicamente macho & 10 & 2.7 \\
Únicamente macho & Únicamente macho & 9 & 2.4 \\
Únicamente macho & Cría inmadura & 6 & 1.6 \\
Únicamente macho & Únicamente hembra & 10 & 2.7 \\
\hline & Total & $\mathbf{9 9}$ & $\mathbf{2 7 . 1}$ \\
\hline
\end{tabular}

No reproducción: En celdas con cría de obrera un 23.5\% de los ácaros no se reprodujo, mientras que en la cría de zángano este parámetro correspondió a un 20.7\%, no encontrándose diferencias significativas $\left(\mathrm{X}^{2}=0.78, \mathrm{p}=0.37\right)$. Sin embargo, es importante indicar que un porcentaje considerable de ácaros que no produjo progenie en la cría de obrera se reprodujo al ser transferidos a la cría de zángano. Por otra parte, sólo un $14.3 \%$ de los ácaros que produjo progenie en la cría de obrera, no logró reproducirse al ser transferidos a la cría de zángano.

Cuadro 5. Parámetros reproductivos del ácaro varroa en celdas con cría de obrera y zángano $(n=362)$.

\begin{tabular}{ccc|cc}
\hline Parámetro reproductivo & \multicolumn{2}{c}{$\begin{array}{c}\text { Celdas con cría de obrera } \\
\text { \# de celdas }\end{array}$} & $\begin{array}{c}\text { Porcentaje } \\
\text { \# de celdas }\end{array}$ & $\begin{array}{c}\text { Porcentaje } \\
\text { Fertilidad }\end{array}$ \\
277 & 76.5 & 287 & 79.3 \\
No reproducción & 85 & 23.5 & 75 & 20.7 \\
\hline Hijas fértiles & 50 & 13.8 & 138 & 38.1 \\
Cría inmadura & 147 & 40.6 & 48 & 13.2 \\
Únicamente hembra & 26 & 7.2 & 55 & 15.2 \\
Únicamente macho & 54 & 14.9 & 46 & 12.8 \\
\hline
\end{tabular}

Ácaros que no se reprodujeron en la cría de obrera y que fueron transferidos a la cría de zángano: Del total de ácaros analizados en las celdas de obrera $(\mathrm{n}=362)$ un $23.5 \%$ (85 ácaros) no produjo progenie. De estos un $74.1 \%(\mathrm{n}=63)$ produjo cría al ser transferidos a las celdas de zángano (mejoró su fertilidad). 
Producción de hijas fértiles: En el 36.5\% de las celdas de zángano, se observó la presencia del macho y al menos una hija adulta (Cuadro 6), con un promedio de $2.3 \pm 1.4$ y una producción de 71 hijas fértiles.

Fecundidad: El promedio de cría producida por ácaro fue de $3.6 \pm 1.5(n=63)$, con un mínimo de un descendiente y un máximo de siete. En la mayoría de las celdas, se observó de tres a cuatro crías, correspondiendo a un $43.0 \%$.

Producción de cría inmadura: El porcentaje de ácaros que produjo cría inmadura en las celdas de zángano correspondió a un 14.1\% (Cuadro 6).

Ácaros con producción de únicamente hijas o únicamente macho: El porcentaje de celdas en las cuales se determinó la presencia de únicamente hijas adultas fue de un 14.1\%, mientras que aquellas con presencia de únicamente macho correspondió a un 9.4\% (Cuadro 6).

No reproducción: El porcentaje de ácaros que no se reprodujo en la cría de obrera y que tampoco lo hizo al ser transferido a la cría de zángano, correspondió a un 25.9\% (Cuadro 6). Se debe indicar que, al finalizar el ciclo reproductivo en la cría de zángano, estos ácaros se alimentaron (presencia de heces) y se observaron saludables (movilidad, locomoción).

Cuadro 6. Parámetros reproductivos de los ácaros que no se reprodujeron en celdas con cría de obrera y que fueron transferidos a celdas con cría de zángano $(n=85)$.

\begin{tabular}{ccc}
\hline Parámetro reproductivo & Número de celdas & Porcentaje (\%) \\
\hline Fertilidad & 63 & 74.1 \\
No reproducción & 22 & 25.9 \\
\hline Hijas fértiles & 31 & 36.5 \\
Cría inmadura & 12 & 14.1 \\
Únicamente hembra & 12 & 14.1 \\
Únicamente macho & 8 & 9.4 \\
\hline
\end{tabular}

\section{Discusión}

Reproducción del ácaro $V$. destructor en cría de obrera: En el presente estudio la fertilidad del ácaro $V$. destructor determinada en cría de obrera de un 76.9\%, es similar a la reportada por Calderón et al. (2003a) de un $76.5 \%$ en condiciones similares. Por otra parte, estudios realizados en México utilizando abejas africanizadas indican una fertilidad de un $88.0 \%$ (Medina \& Martin 1999). Mientras que, en Brasil, se ha observado un aumento en la fertilidad de varroa, pasando de un 53.0\% (Camazine 1986; Moretto et al. 1997; Rosenkranz 1999) a un 75.0\% (Corrêa-Marques et al. 2003; Garrido et al. 2003). La causa de este incremento puede deberse a la detección en Brasil de ácaros del halotipo coreano, el cual es considerado como el más patógeno (anteriormente el halotipo reportado era el Japonés) (De Guzmán et al. 2001).

Se debe indicar, que aún cuando el porcentaje de fertilidad de varroa en celdas con cría de obrera fue considerable, la producción de hijas fértiles fue de apenas un 16.5\%. Las hijas fértiles son las que 
Rev. Ciencias Veterinarias, Vol. 37, N² 2, [44-61], E-ISSN: 2215-4507, julio-diciembre, 2019

DOI: https://doi.org/10.15359/rcv.37-2.5

Ciencias

URL: http://www.revistas.una.ac.cr/index.php/veterinaria/index

aseguran el crecimiento de la población del ácaro varroa dentro de la colmena. En Costa Rica, otras investigaciones reportan una producción de hijas fértiles de un 25.0\% (Calderón et al. 2003a), mientras que en México y Brasil se ha encontrado hasta un 40.0\% (Corrêa-Marques et al. 2003). Schneider et al. (2004), indican que la producción de hijas viables puede estar influenciada por factores como el clima, el halotipo del ácaro y la raza de la abeja.

El promedio de hijas fértiles producidas por ácaro fue de $1.3 \pm 0.5$, el cual es similar al considerado por Vandame et al. (2000) en México de 1.35 y por Moretto et al. (1995) en Brasil de 1.54 (con alguna variante en la medición). En este estudio, un total de 732 ácaros produjeron en un ciclo reproductivo 160 hijas fértiles, lo cual hace que el crecimiento de la población de varroa sea lento.

En celdas de obrera se encontró un máximo de seis huevos. Resultados semejantes han sido reportados por diferentes autores (Ifantidis 1983; Martin 1995a; Al-Ghamdi \& Hoopingarner 2003). Además, el promedio de hijas producidas por celda de $2.9 \pm 1.3$ es similar al encontrado en abejas africanizadas en Texas de $2.29 \pm 0.1$ (De Guzmán et al. 2001). Por otra parte, Calderón et al. (2003a) determinó un promedio de $3.4 \pm 1.3$.

En la presente investigación un 38.2\% de los ácaros produjo cría inmadura, lo cual es semejante al encontrado en Brasil (Corrêa-Marques et al. 2003). Este porcentaje de ácaros corresponde a aquellos que inician la oviposición tardíamente en el ciclo, lo cual causa que estos estadios no tengan el tiempo suficiente para alcanzar la fase adulta.

En celdas de obrera un $8.5 \%$ de los ácaros produjo únicamente hijas, lo cual es similar a lo encontrado por Calderón et al. (2003a) de un 8.2\%. Este parámetro representa a los ácaros que no logran copular y por ello permanecen infértiles en ciclos reproductivos sucesivos (De Ruijter \& Pappas 1983). Martin (1995) indicó que un porcentaje de hembras sin fecundar no son capaces de producir progenie en nuevos ciclos reproductivos. Una de las posibles causas de la ausencia de macho dentro de la celda, es su muerte temprana (en estadios inmaduros). En este estudio sólo $0.3 \%$ de los machos adultos, se encontraron muertos en celdas de obrera, sin embargo, otros autores describen que este fenómeno se presenta con cierta frecuencia afectando directamente la dinámica reproductiva del ácaro (Martin et al. 1997).

En un $13.7 \%$ de las celdas con cría de obrera, se encontró la presencia de únicamente macho. Este dato es semejante a lo observado por Calderón et al. (2003a) de un 16.4\% y al reportado por Medina \& Martin (1999) de un 11\%. De Ruijter (1987) señala que las madres infértiles no son capaces de aparearse con sus hijos en la misma celda ni con otros machos en un nuevo ciclo, debido a que la copula ocurre inmediatamente después de que la hembra alcanza el estadio adulto. Por otro lado, ácaros que inician la oviposición tardíamente, pueden producir únicamente el macho adulto y estadios inmaduros, los cuales no tienen suficiente tiempo para desarrollarse hasta convertirse en hijas adultas.

En este estudio un $23.1 \%$ de los ácaros no se reprodujo dentro de las celdas de obrera. En una investigación similar realizada por Calderón et al. (2003a), se determinó que un 23.5\% de los ácaros no produjo progenie. Asimismo, Corrêa-Marques et al. (2003) reportó que un 22\% no se reprodujo en abejas africanizadas en Brasil. Se debe mencionar que la mayoría de los ácaros que no se reprodujeron se observaron en buenas condiciones. 
Reproducción del ácaro $\boldsymbol{V}$. destructor en celdas con cría de zángano: La fertilidad del ácaro varroa en celdas con cría de zángano fue de 79.3\%, similar a la reportada en Brasil de un 77\% (Garrido et al. 2003). Por otra parte, en abejas europeas se ha observado una mayor fertilidad la cual varía de un $84 \%$ hasta un 93\% (Garrido et al. 2003; Al-Ghamdi \& Hoopingarner 2003). Por lo anterior, se considera que la abeja europea es más susceptible a varroa que la africanizada. En celdas de zángano, un alto porcentaje de los ácaros produjo hijas fértiles. Si se considera únicamente las hembras con progenie, este corresponde a un $48 \%(n=287)$. Medina \& Martin (1999) reportan que un 43\% de los ácaros produjo cría viable en abejas africanizadas en México. Por otro lado, el promedio de cría fértil producido por ácaro fue de $2.1 \pm 0.9$, el cual es similar al reportado por Martin \& Kryger (2002) en abejas africanas, A. m. scutellata, de 2.2. Tomando en cuenta la cantidad de cría fértil producida durante un ciclo reproductivo por 362 ácaros, la cual fue de 290 hijas, el número de ciclos por ácaro y la disponibilidad de cría de zángano en una colmena, se puede indicar que estas celdas son fundamentales para el desarrollo de la población del ácaro varroa.

Se determinó un máximo de siete huevos en celdas con cría de zángano, lo cual ha sido descrito por diferentes autores (Ifantidis 1983; Al-Ghamdi \& Hoopingarner 2003). Asimismo, el promedio de cría producida por celda fue de $3.7 \pm 1.6$. Martin \& Kryger (2002) reportan un promedio de cría de $4.9 \pm 1.0$ en A. m. scutellata. Por otra parte, del total de descendientes producidos, un $26 \%$ correspondió a hijas fértiles, las cuales participan en el crecimiento de la población del ácaro dentro de la colonia. El resto de la cría correspondió a estadios inmaduros, ácaros de un sólo sexo y al macho.

En el 13.3\% de las celdas de zángano, se observó la presencia de cría inmadura. Martin et al. (1997) señalan que la edad del ácaro afecta su capacidad reproductiva, indicando que ácaros jóvenes pueden fallar al iniciar su vida reproductiva, produciendo únicamente estadios inmaduros y que aquellos de edad avanzada, pueden presentar una reducción en la cantidad de huevos ovipositados.

Un 15.2\% de las celdas de zángano presentó únicamente hijas, lo cual es similar a lo reportado por Martin \& Kryger (2002) en A. m. scutellata. La mortalidad del macho es una de las posibles causas que explica su ausencia, siendo el aplastamiento mecánico que se produce por los movimientos de la cría, el más común.

Las celdas de zángano en las que se produjeron sólo machos correspondieron a un 12.7\%. Martin \& Kryger (2002), reportan un 20\% en abejas africanas. La presencia de sólo macho en la celda puede estar relacionada con ácaros infértiles y ácaros que se retrasan en el inicio de la oviposición. Independientemente de la causa de este hallazgo, estos machos no participan en el crecimiento de la población de varroa, ya que mueren dentro de la celda de cría una vez que la abeja emerge.

En el presente estudio un $20.7 \%$ de los ácaros no produjo progenie en celdas con cría de zángano. En investigaciones realizadas en Uruguay y Brasil, Martin \& Medina (2004) mencionan que la cantidad de ácaros que no se reproducen varía desde un 13 hasta un 30\%. La edad del ácaro es uno de los factores que afecta directamente su capacidad reproductiva. A la fecha, existen pocos datos relacionados con el número de ciclos reproductivos que puede realizar el ácaro varroa. Martin et al. (1997), reporta que este ácaro en condiciones naturales puede completar de dos a tres ciclos durante su vida. Por otra parte, De Ruijter (1987) en condiciones artificiales demostró que varroa fue capaz de reproducirse durante siete ciclos sucesivos, produciendo más de 30 huevos. 
Rev. Ciencias Veterinarias, Vol. 37, N² 2, [44-61], E-ISSN: 2215-4507, julio-diciembre, 2019

DOI: https://doi.org/10.15359/rcv.37-2.5

URL: http://www.revistas.una.ac.cr/index.php/veterinaria/index

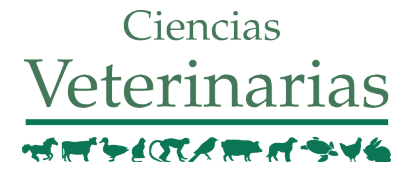

Comparación del comportamiento reproductivo del ácaro varroa en celdas con cría de obrera y zángano: La fertilidad del ácaro varroa fue ligeramente mayor en la cría de zángano en comparación con la cría de obrera. Se conoce que varroa presenta una mayor atracción hacia las celdas de zángano (Boot et al. 1995b; Calis 2001; Calderone \& Kuenen 2003), razón por la cual podría esperarse una mejor fertilidad en este tipo de cría. A su vez, debe considerarse que factores propios del ácaro, como la edad, podrían afectar directamente la fertilidad. Asimismo, la producción de hijas fértiles fue significativamente superior en la cría de zángano. Este resultado permite determinar que varroa, además de infestar en mayor proporción a este tipo de cría, también presenta un mejor éxito reproductivo dentro de ella, produciendo hasta 2.8 veces más hijas fértiles durante un ciclo reproductivo. Por otra parte, una cantidad considerable de ácaros que únicamente produjo cría inmadura o de un sólo sexo en celdas de obrera, logró producir hijas fértiles al ser transferidos a celdas de zángano. Uno de los principales factores asociados a la producción de hijas fértiles en cría de zángano comparado con obrera, es el mayor tiempo de sellado de la celda, el cual permite que más crías logren alcanzar el estadio adulto (Medina \& Martin 1999). Además, es probable que diferencias morfológicas y fisiológicas (composición de la hemolinfa) entre ambos tipos de cría, favorezcan en mayor medida la habilidad reproductiva del ácaro en celdas con cría de zángano. Las larvas de zángano requieren una mayor cantidad de carbohidratos y proteínas, además acumulan más lípidos y su crecimiento es más prolongado (Hrassnigg \& Crailsheim 2005). La cantidad de cría producida por ácaro fue superior en celdas de zángano, encontrándose en promedio 1.1 más crías por celda. Aun cuando no todos los estadios logran alcanzar la fase adulta, es notorio que la cría de zángano presenta condiciones más favorables que la cría de obrera para que varroa produzca progenie.

La presencia de cría inmadura fue significativamente más alta en celdas de obrera, alcanzando más de un $40.0 \%$, mientras que en celdas de zángano fue inferior a un 15.0\%. Como se indicó anteriormente, la cría de zángano representa un estímulo apropiado para que el ácaro inicie la oviposición a las 60 horas luego de sellada la celda y por tanto, sea capaz de producir un alto porcentaje de cría viable.

La presencia de ácaros que produjeron únicamente hijas fue mayor en celdas con cría de zángano, mientras que la producción de únicamente macho fue similar en los dos tipos de cría. Ambos parámetros representan alrededor de un $30 \%$ de los ácaros, tanto en celdas de obrera como de zángano. Como se mencionó anteriormente, la ausencia de macho provoca que las hembras permanezcan infértiles y la producción de sólo macho no favorece el desarrollo reproductivo del ácaro. En los dos casos no hay producción de hijas viables, lo cual incide negativamente en la dinámica poblacional de varroa.

Al evaluar de manera general los resultados, se determinó que la cantidad de ácaros que no lograron reproducirse fue ligeramente mayor en la cría de obrera. Por otra parte, el análisis individual de las celdas determinó que un número importante de ácaros que no se reprodujo en celdas de obrera, logró producir progenie al ser transferidos a celdas de zángano. Por lo anterior, es posible señalar que en celdas con cría de zángano el ácaro varroa presenta mejor reproducción.

Las razones fisiológicas, por las cuales los ácaros no se reproducen en las celdas con cría no se conocen con exactitud, sin embargo, se pueden indicar diferentes factores involucrados. Martin et al. (1997), observó que el nivel normal de ácaros que no se reproduce en celdas de obrera en abejas europeas es del 15\%, lo cual puede deberse a la muerte prematura del macho. Por otro lado, en abejas A. cerana en Papua Nueva Guinea y A. mellifera en Brasil, se observó que un alto porcentaje de ácaros que no se 
reprodujeron en cría de obrera, eran fisiológicamente capaces de producir progenie. En el presente estudio, la mayoría de los ácaros que no se reprodujo se observaron activos y saludables. Por otra parte, la edad del ácaro es otro de los factores que afecta directamente su capacidad reproductiva (Martin \& Kemp 1997).

Ácaros que no se reprodujeron en la cría de obrera y que fueron transferidos a la cría de zángano: En términos generales la mayoría de ácaros provenientes de celdas de obrera mejoraron su reproducción al ser introducidos a celdas de zángano. Diferencias morfológicas y fisiológicas relacionadas con el metabolismo, el consumo energético y la composición de la hemolinfa en los dos tipos de cría, pueden ser factores determinantes en la habilidad reproductiva de varroa (Hrassnigg \& Crailsheim 2005).

Este estudio se caracterizó porque la habilidad reproductiva del mismo ácaro fue evaluada en dos ciclos sucesivos, bajo condiciones similares (edad de la larva, temperatura, humedad, entre otras), siendo la variable principal el tipo de cría (obrera o zángano). Uno de los principales hallazgos, es que un alto porcentaje de ácaros que no se reprodujo en la cría de obrera, logró reproducirse luego de ser transferidos a celdas de zángano. Algunas investigaciones, han relacionado la composición de la hemolinfa de la abeja con el comportamiento reproductivo del ácaro (Contzen et al. 2004; Hrassnigg \& Crailsheim 2005). Por otro lado, las celdas con cría de zángano tienen un mayor tamaño que las de obrera (aproximadamente el doble), lo cual podría ser un factor que beneficie las condiciones generales para la reproducción de varroa (Boot et al. 1995b; Wilkinson \& Smith 2002; Al-Ghamdi \& Hoopingarner 2003). Hrassnigg \& Crailsheim (2005), encontraron que en la celda de zángano la disponibilidad de oxígeno es mayor que en la de obrera, lo cual podría favorecer la capacidad reproductiva de varroa.

Otro de los resultados más relevantes, es que un 36.5\% de los ácaros que se reprodujo en las celdas de zángano, produjo hijas fértiles. Tomando en cuenta que estos ácaros no produjeron progenie en celdas de obrera y que lograron producir hijas viables en las de zángano, se puede indicar que aun cuando la presencia de este tipo de cría en la colmena es estacional, puede considerarse un factor determinante en el crecimiento de la población de varroa.

Un 37.6\% de los ácaros que se reprodujo en la cría de zángano, sólo produjo cría inmadura o cría de un sólo sexo. Es importante indicar, que aun cuando esta población de ácaros no incide directamente en el crecimiento de la población (no hubo producción de hijas viables), en términos generales mostró una mejoría reproductiva, ya que logró producir descendencia.

Un 25.9\% de los ácaros no se reprodujo ni en celdas con cría de obrera, ni al ser transferidos a celdas con cría de zángano. Estos ácaros se observaron activos y con abundante presencia de heces en la celda. Además, en ambos tipos de cría el desarrollo y apariencia general de la pupa fue el óptimo. La causa específica de este comportamiento no se conoce, sin embargo, se puede indicar que la edad de varroa pudo influir negativamente. Es por ello, que aun cuando infesten una celda con cría en condiciones favorables no serán capaces de reproducirse.

\section{Conclusiones}

Se puede concluir que la fertilidad del ácaro $V$. destructor fue similar en ambos tipos de cría. Sin embargo, se observaron diferencias reproductivas. En celdas con cría de zángano una cantidad considerable de ácaros presentó hijas fértiles durante un ciclo reproductivo, mientras que en celdas con 
cría de obrera se encontró únicamente un 13.8\%. Uno de los hallazgos más relevantes en este estudio, es que un alto porcentaje de ácaros que no se reprodujo en la cría de obrera, logró reproducirse luego de ser transferidos a celdas de zángano. En términos generales, varroa mejoró su comportamiento reproductivo al ser transferido a celdas con cría de zángano. Por lo anterior, se debe indicar que la cría de zángano es esencial para el desarrollo y crecimiento de la población del ácaro $V$. destructor en colmenas de abejas africanizadas bajo condiciones tropicales.

\section{Rererencias}

Beetsma, J., Boot, W.J. \& Calis, J. 1999. Invasion behaviour of Varroa jacobsoni Oud: from bees into brood cells. Apidologie 30(2-3): 125-140. Doi: 10.1051/apido:19990204

Boot, W.J., Schoenmaker, J., Calis, J. \& Beetsma, J. 1995a. Invasion of Varroa jacobsoni into drone brood cells of honey bee, Apis mellifera. Apidologie 26(2): 109-118. Doi: 10.1051/apido:19950204

Boot, W.J., Van Baalen, M. \& Sabelis, M.W. 1995b. Why do Varroa mites invade worker brood of the honey bee despite lower reproductive success? Behav. Ecol. Sociobiol. 36(4): 283-289. Doi: 10.1007/ BF00165837

Calderón, R.A., Sommeijer, M.J., de Ruijter, A. \& van Veen, J.W. 2003a. The reproductive ability of Varroa destructor in worker brood of Africanized and hybrid honey bees in Costa Rica. J. Apicult. Res. 42(4): 65-67. Doi: 10.1080/00218839.2003.11101095.

Calderón, R.A., van Veen, J., Arce, H.G. \& Esquivel, M. 2003b. Presence of deformed wing and Kashmir bee virus in Africanized honey bee colonies in Costa Rica infested with Varroa destructor. Bee World 84(3): 112-116. Doi: 10.1080/0005772X.2003.11099586.

Calderone, N.W. \& Kuenen, L.P.S. 2003. Differential tending of worker and drone larvae of the honey bee, Apis mellifera, during the 60 hours prior to cell capping. Apidologie 34: 543-552. Doi: 10.1051/ apido:2003054.

Calis, J.N.M., Boot, W.J., Beetsma, J., van den Eijnde, J.H., de Ruijter, A. \& van der Steen, J.J.M. 1999. Effective biotechnical control of varroa: applying knowledge on brood cell invasion to trap honey bee parasites in drone brood. J. Apicult. Res. 38(1-2): 49-61. Doi: 10.1080/00218839.1999.11100995.

Calis, J.N.M. 2001. Parasite-host interaction between the varroa mite and the honey bee: A contribution to sustainable varroa control. Master Thesis. Wageningen University. NL. p. 55-60.

Camazine, S. 1986. Differential reproduction of the mite, Varroa jacobsoni (Mesostigmata:Varroidae), on Africanized and European honey bees (Hymenoptera:Apidae). Ann. Entomol. Soc. Am. 79(5): 801-803. Doi: 10.1093/aesa/79.5.801.

Clarke, G.M. 1989. Statistics and experimental design. $2^{\text {nd }}$ Edition. Edward Arnold, Newcastle, U.K. p. 28-30.

Contzen, C., Garedew, A., Lamprecht, I. \& Schmolz, E. 2004. Calorimetrical and biochemical investigations on the influence of the parasitic mite Varroa destructor on the development of honeybee brood. Thermochim. Acta 415(1-2): 115-121. Doi: 10.1016/j.tca.2003.06.006 
Corrêa-Marques, M.H., Medina, L., Martin, S.J. \& De Jong, D. 2003. Comparing data on the reproduction of Varroa destructor. Genet. Mol. Res. 2(1): 1-6.

De Guzmán, L., Rinderer, T.E., Collins, A. \& Lancaster, V.A. 2001. Attractiveness of Africanized honey bee brood from Southern Texas to Varroa destructor infestation. Am. Bee J. 142(2): 130-132.

De Jong, D. 1997. Mites: Varroa and other parasites of brood. In Morse, R.A. \& Flottum, K. (Eds.). Honey bee pests, predators, and diseases, $3^{\text {rd }}$ Edition. A.I. Root Company, Ohio. p. 281-327.

De Ruijter, A. 1987. Reproduction of Varroa jacobsoni during successive brood cycles of the honeybee. Apidologie 18(4): 321-326. Doi: 10.1051/apido:19870403.

De Ruijter, A. \& Pappas, N. 1983. Karyotype and sex determination of Varroa jacobsoni Oud. In Cavalloro, R. (Ed.). Varroa jacobsoni Oud. affecting honeybees: present status and needs. University of Wageningen, NL. p. 41-44.

Garrido, C., Rosenkranz, P., Paxton, R.J. \& Gonçalves, L.S. 2003. Temporal changes in Varroa destructor fertility and haplotype in Brazil. Apidologie 34(6): 535-541. Doi: 10.1051/apido:2003041.

Al-Ghamdi, A. \& Hoopingarner, R. 2003. Reproductive biology of Varroa jacobsoni Oud. in worker and drone brood of the honey bee Apis mellifera L. under Michigan conditions. Pak. J. Biol. Sci. 6(8): 756-761. Doi: 10.3923/pjbs.2003.756.761.

Hrassnigg, N. \& Crailsheim, K. 2005. Differences in drone and worker physiology in honeybees (Apis mellifera). Apidologie 36: 255-277. Doi: 10.1051/apido:2005015.

Ifantidis, M.D. 1983. Ontogenesis of the mite Varroa jacobsoni in worker and drone honeybee brood cells. J. Apicult. Res. 22(3): 200-206. Doi: 10.1080/00218839.1983.11100588.

Martin, S.J. 1995a. Ontogenesis of the mite Varroa jacobsoni Oud. in worker brood of the honeybee Apis mellifera L. under natural conditions. Exp. Appl. Acarol. 19(4): 199-210. Doi: 10.1007/BF00130823

Martin, S.J. 1995b. Reproduction of Varroa jacobsoni in cells of Apis mellifera containing one or more mother mites and the distribution of these cells. J. Apicult. Res. 34(4): 187-196. Doi: 10.1080/00218839.1995.11100904.

Martin, S.J. \& Kemp, D. 1997. Average number of reproductive cycles performed by Varroa jacobsoni in honey bee (Apis mellifera) colonies. J. Apicult. Res. 36(3-4): 113-123. Doi: 10.1080/00218839.1997.11100937.

Martin, S.J., Holland, K. \& Murray, M. 1997. Non-reproduction in the honeybee mite Varroa jacobsoni. Exp. Appl. Acarol. 21(8): 539-549.

Martin, S.J. \& Kryger, P. 2002. Reproduction of Varroa destructor in South African honey bees: does cell space influence Varroa male survivorship? Apidologie 33(1): 51-61. Doi: 10.1051/apido:2001007.

Martin, S.J. \& Medina, L.M. 2004. Africanized honeybees have a unique tolerance to Varroa mites. Trends Parasitol. 20(3): 112-114. Doi: 10.1016/j.pt.2004.01.001. 
Medina, L.M. \& Martin, S.J. 1999. A comparative study of Varroa jacobsoni reproduction in worker cells of honey bees (Apis mellifera) in England and Africanized bees in Yucatan, Mexico. Exp. Appl. Acarol. 23(8): 659-667. Doi: 10.1023/A:1006275525463

Medina, L.M., Martin, S.J., Espinosa-Montaño, L. \& Ratnieks, F.L.W. 2002. Reproduction of Varroa destructor in worker brood of Africanized honey bees (Apis mellifera). Exp. Appl. Acarol. 27(1-2): 79-88. Doi: 10.1023/A:1021579113907

Moretto, G.A., Pillati, A., De Jong, D., Gonçalves, L.S. \& Cassini, F.L. 1995. Reduction of varroa infestation in the state of Santa Catarina, in Southern Brazil. Am. Bee J. 6: 498-499.

Moretto, G., Gonçalves, L. \& De Jong, D. 1997. Relationship between food availability and the reproductive ability of the mite Varroa jacobsoni in Africanized bee colonies. Am. Bee J. 137(1): 67-69.

Ravazzi, G. 1995. Curso de Apicultura, 2 ${ }^{\text {nd }}$ Edition. De Vecchi S.A., Barcelona. p. 70-71.

Rosenkranz, P. 1999. Honey bee (Apis mellifera L.) tolerance to Varroa jacobsoni Oud. in South America. Apidologie 30(2-3): 159-172. Doi: 10.1051/apido:19990206

Schneider, S., DeGrandi-Hoffman, G. \& Smith, D.R. 2004. The African honey bee: factors contributing to a successful biological invasion. Annu. Rev. Entomol. 49: 351-376. Doi: 10.1146/annurev. ento.49.061802.123359.

Vandame, R., Colin, M.E., Morand, S. \& Otero-Colina, G. 2000. Levels of compatibility in a new hostparasite association: Apis mellifera/Varroa jacobsoni. Can. J. Zool. 78(11): 2037-2044. Doi: 10.1139/ cjz-78-11-2037.

Wilkinson, D. \& Smith, G.C. 2002. Modelling the efficiency of sampling and trapping Varroa destructor in the drone brood of honey bees (Apis mellifera). Am. Bee J. 142(3): 209-212. 